\title{
Formação crítica mediada pelas tecnologias digitais de informação e comunicação: um desenho de pesquisa qualitativa
}

\author{
Critical education with information and communication technology: a \\ qualitative research design model
}

\section{Formación crítica mediada por las tecnologías digitales de información y Comunicación: un diseño de investigación cualitativa}

\author{
Ingrid Ingrid Nicola Souto ${ }^{1}$ \\ Andrea Brandão Lapa ${ }^{2}$ \\ http://dx.doi.org/10.5216/31836
}

\begin{abstract}
Resumo
Este artigo trata da apresentação de um modelo qualitativo de investigação acerca da apropriação de Tecnologias Digitais de Informação e Comunicação (TDIC) na formação crítica de professores de Ciências. A pesquisa foi ancorada na perspectiva da Teoria Crítica e da Mídia-Educação, que investem em uma apropriação crítica e criativa das TDIC como ação transformadora. Para tanto, foi desenvolvido um o instrumento análise, a partir dos elementos: contexto, diálogo, reflexão e ação, que fazem parte da Teoria Freiriana de educação dialógica problematizadora, que foram analisados com a ajuda do software Web Qualitative Data Analysis - WebQDA. Como resultado, a criação de um modelo de análise qualitativa de práticas pedagógicas com TDIC contribui para a investigação da própria prática por professores que buscam promover uma formação crítica.
\end{abstract}

Palavras-chave: Metodologia Qualitativa. Formação Crítica. Tecnologias Digitais da Informação e Comunicação. WebQDA.

\begin{abstract}
From a social criticism standpoint, the study deals with future teachers education for a critical and creative appropriation of ICT as a pedagogical tool. On this sense, the article parallels the theoretical framework adopted (Media Education perspective, Critical Theory and Paulo Freire's problematization method) with the current challenges faced on Science teaching. An empirical model was developed to analyze a course in both dimensions: the discipline (learning perspective) and the meta-discipline (teaching planning). The instrument uses categories of analysis such as context, dialogue, reflection and action and WebQDA as a resource for qualitative analysis. As a result, the investigation contributes to the exploration of teaching practices through qualitative research, while is able to confirm the hypothesis of the discipline as a relevant space for critical formation of future teachers.
\end{abstract}

Keywords: Qualitative methodology. Critical thinking. Information and Communication Technology. Science Education. WebQDA.

\footnotetext{
${ }^{1}$ Mestra pelo Programa de Pós-graduação em Educação Científica e Tecnológica, Universidade Federal de Santa Catarina (PPGECT/UFSC). E-mail: ingrid.souto@gmail.com

${ }^{2}$ Professora do Centro de Ciências da Educação da Universidade Federal de Santa Catarina (CED/UFSC).

Brasil, Santa Catarina, Florianópolis. E-mail: andrea.lapa@ufsc.br
} 


\section{Resumen}

En este artículo se presenta un modelo de investigación cualitativa sobre la apropiación de Tecnologías Digitales de información y Comunicación en la formación crítica de profesores de Ciencias. El marco teórico se basa en la Teoría Crítica y en la Educación para los Medios, que han defendido la apropiación crítica y creativa de tecnologías como acción transformadora. Con este fin, fue desarrollado un instrumento de investigación de cuatro categorías de la educación dialógica y problematizadora de Paulo Freire: contexto, diálogo, reflexión y acción. Una análisis de contenido fue realizada con la ayuda del software Web Qualitative Data Analysis - WebQDA. Como resultado, la creación de este modelo para el análisis cualitativo de las prácticas pedagógicas con tecnologías contribuye para que maestros investiguen su propia práctica cuando buscan promover una formación crítica de sus alumnos.

Palabras clave: Metodología cualitativa. Formación crítica. Tecnologías digitales de información y comunicación. WebQDA.

\section{INTRODUÇÃO}

As inovações tecnológicas e a disseminação do acesso às tecnologias causaram diversas transformações no mundo contemporâneo. Essas transformações foram impulsionadas principalmente a partir dos computadores e da Internet, que possibilitaram uma revolução baseada nas tecnologias de informação e comunicação. Em especial, devido à difusão, estas novas mídias digitais são identificadas como Tecnologias Digitais de Informação e Comunicação - TDIC (ALMEIDA, 2010). Mais do que falar do desenvolvimento de uma nova ferramenta tecnológica, trata-se de uma inovação que alterou as formas de pensar, sentir e agir da sociedade. Elas permearam o cotidiano, o espaço de vivência possui novas formas de relações sociais, já que trata-se da formação de uma nova cultura, uma cultura digital (PRETTO; ASSIS, 2008), que é um processo crescente de reorganização de todas as esferas da ação humana mediadas pelas tecnologias digitais.

Contudo, parece ainda atual a denúncia feita pela Escola de Frankfurt, já que se faz necessário um olhar crítico sobre os fenômenos da indústria cultural, que reduzem tudo a massa, impedindo a formação do sujeito produtor de cultura e de conhecimentos (RUDIGER, 2011). Se por um lado o poder está no sujeito e na forma de apropriação crítica desses meios, de outro ele está limitado às reais condições que encontra para fazer essa apropriação crítica, seja pelo acesso aos meios ou à formação para um uso crítico. Dito de outra forma, a imposição acelerada dessas tecnologias pode "aprofundar o processo de esquizofrenia entre a máscara de modernização que a pressão dos interesses transacionais realiza e as possibilidades reais de apropriação e identificação cultural" (MARTIN-BARBERO, 2004, p. 179).

Rudiger (2011) afirma que dois discursos divergentes emergem sobre a questão da apropriação das tecnologias pela sociedade. De um lado, há os tecnófilos, com uma visão mais 
liberal, que assumem o uso instrumentalista do produto pelo viés da eficiência. Prometem um mundo melhor através da tecnologia, que deve ser vista como um fator de progresso e que os obstáculos que nela se encontram serão solucionados com pesquisas e desenvolvimento de novos artefatos. De outro, há os tecnófobos, com uma visão mais socialista, que tecem conceitos e valores historicamente construídos e, por isto, assumem a tecnologia como uma armadilha progressista, um elemento nocivo, construído pela humanidade, que tende não apenas a agredir, mas ameaçar a sobrevivência. Entretanto, ambos parecem não avançar muito, pois, se de fato fazemos parte de uma sociedade tecnológica, em rede, conectada (e isto é uma realidade inevitável) o tratamento dual entre tecnófilos e tecnófobos tem seus limites.

Em busca de um ângulo transversal (não tecnófilo e não tecnófobo) que possa contribuir para tornar o indivíduo capaz de discernir criticamente os aspectos positivos e negativos, os altos e baixos e as perdas e ganhos implicados na trajetória do desenvolvimento das novas tecnologias (KELLNER, 2001), existe a possibilidade de uma terceira tendência, a dos cibercriticistas, que propõe levar em conta os problemas e desafios do sujeito social para refletir sobre as conexões da cibercultura e o poder (político, social e econômico) (RUDIGER, 2011). Porque a tecnologia, principalmente os computadores e a internet, pode promover na comunicação uma mudança cooperativa e emancipatória, mas somente se forem devidamente apropriados através da reflexão filosófica e a ação política, e se estiverem a serviço de novas formas de sociabilidade. Portanto, uma visão crítica estaria menos ligada à resistência e mais às formas críticas de inserção de sujeitos na cultura digital, como protagonistas, autores e coautores.

As mudanças sociais que as TIDC catalisam na sociedade contemporânea também podem ser sentidas na área da Educação, que urge por reflexões sobre as formas de apropriação das TDIC, já que esses mecanismos podem ser "eficazes" se usados para a reprodução e o controle social através do processo de transmissão de conhecimentos, técnicas, valores e representações sociais e modelos da cultura (KELLNER, 2004).

\section{A EDUCAÇÃO COM AS TECNOLOGIAS DIGITAIS DA INFORMAÇÃO E COMUNICAÇÃO (TDIC)}

No cenário das transformações sociais contemporâneas, salientamos especialmente a preocupação com a rapidez do desenvolvimento tecnológico e os impactos que promovem na educação. Em particular, o fato de que a rapidez dessas mudanças nem sempre permitem uma reflexão sobre as práticas pedagógicas com uso dos recursos digitais para formação do sujeito, e isto favorece as práticas pedagógicas tradicionais, ou seja, "as velhas práticas mascaradas de 
novas". Dessa forma, a preocupação da educação com TDIC, de acordo com Pretto e Assis (2008, p.80) é que a

[...] incorporação dessas tecnologias não pode se dar meramente como ferramentas adicionais, complementares, como meras animadoras dos tradicionais processos de ensinar e de aprender. As tecnologias necessitam ser compreendidas como elementos fundantes das transformações que estamos vivendo [...]. (PRETTO; ASSIS, 2008, p. 80)

Por isso, o desafio não é por uma pedagogia do equipamento e sim por uma cultura digital presente nos currículos, nos conteúdos e no cotidiano da escola, não como um acessório nos processos educacionais (PRETTO, 2013). Uma ação educativa viável hoje, um ângulo transversal, requer buscar alternativas de formação com ênfase na criticidade do sujeito, que já utiliza as TDIC à revelia da escola e do professor. Pois, se não enfrentarem este desafio, os recursos tecnológicos servirão apenas para apropriação mais "performática" (BELLONI, 2010), reconhecida como inovadora pela simples introdução de um mero recurso tecnológico na prática educativa. Ou seja, as escolas estarão conectadas,

Mas o sistema educacional, em última instância, pode permanecer o mesmo: hierárquico, vertical, centralizado de forma exagerada. Uma velha escola velha, com cara de moderna. Ou, quem sabe, pós moderna!. (BONILLA apud PRETTO, 2002, p.124).

Logo, a questão primordial é como educar e educar-se na cultura digital, como a educação pode romper com o paradigma de transmissão, instrução e reprodução. Por essa razão, retomamos que a preocupação deste estudo está no papel da educação para a formação do sujeito diante desta cultura digital, que apresenta diferentes caminhos que podem tanto alienar o indivíduo, quando possibilitar a formação de sujeitos produtores de cultura e de conhecimento (DIAS apud PRETTO, 2006).

Com isso, partimos do conceito de Mídia-Educação para/sobre ou através dos meios que analisa este contexto em duas dimensões: para o uso da mídia como ferramenta pedagógica e para os conteúdos éticos e estéticos dos meios (BELLONI, 2005). Dessa forma, a finalidade da mídia-educação é formar cidadãos competentes para a vida em sociedade, o que inclui a apropriação crítica e criativa de todos os recursos técnicos à disposição desta sociedade.

Ou seja, a mídia-educação constitui um espaço de reflexão teórica sobre as práticas culturais e também se configura como um fazer educativo, no encontro da dupla dimensão do "fazer a partir dos sentidos culturais" da sociedade e "ensinar a fazer com significado" na educação, pois nesta 
perspectiva a mídia-educação pode ser uma possibilidade frente aos desafios de reaproximar cultura, educação e sociedade. (FANTIN, 2006, p.37).

Rivoltella (1997) também destaca que uma intervenção mídia-educativa pode ser entendida como práxis educativa com um campo metodológico e de intervenção didática; e como instância de reflexão teórica sobre esta práxis - com objetivos, metodologias e avaliação. Neste sentido, não pode prescindir de dois aspectos: uma atividade e uma reflexão teórica, que guiam e sustentam esta práxis (RIVOLTELLA, 1997, p. 13, apud FANTIN, 2006).

Contrariando a lógica do modelo tradicional, a pedagogia do pensamento demostrou como a "dominação e a opressão produzidas dentro dos diversos mecanismos de escolarização ignoraram os espaços educacionais, como locais políticos e culturais" (GIROUX, 1997, p.25). Além disso, para o referido autor, compreender a escola como um espaço político, como esferas públicas democráticas, é o que podemos chamar de primeiro passo em busca de uma pedagogia contra-hegemônica, para possibilitar aos estudantes habilidades e conhecimentos necessários para serem atuantes críticos e comprometidos com o desenvolvimento de um mundo livre de opressão e exploração; para que possam interpretar o mundo criticamente e mudá-lo quando necessário, ou seja, educar para a ação transformadora (Ibid, 1997).

Por isto, o questionamento central aqui é: como a educação na Cultura Digital pode promover uma formação crítica? Pois, uma educação contemporânea de qualidade, tem seus limites, mas um primeiro passo seria confrontar a lógica transmissiva que pretende apenas programar e controlar os indivíduos para reproduzir e consumir.

Neste contexto, encontramos o referencial de luta pela transformação e emancipação crítica dos indivíduos em Freire (importante para o Brasil). Ele propõe a educação como espaço de liberdade, em que educador e educando são sujeitos do processo e não meros objetos aptos a reproduzir e consumir.

Na educação bancária, "o ato educacional” é constituído por ações, como: depósito, transferência, transmissão passiva de valores e conhecimentos, ou seja, ações iguais às operações essencialmente bancárias. Por isto, compreendemos que a análise de Freire, sobre esta "operação bancária" do contexto da educação da década de 60 ainda é tão coerente e atual. Isto porque, hoje se faz presente na educação online e/ou educação com TDIC, que têm programas imediatistas de treinamentos. 
Em oposição a este modelo bancário de educação, Freire apresentou outros caminhos. Buscou uma educação como prática da liberdade, pautada em reflexões sobre a realidade existencial, visto que "não há educação fora das sociedades humanas e não há homens vazios"(FREIRE, 2011a, p.51).

Na educação como prática para a liberdade o diálogo é essencial, porque é através da palavra e não no silêncio que os homens se fazem, possibilitando uma postura de autorreflexão e reflexão sobre o seu tempo e espaço (FREIRE, 2011a). Para Freire, o diálogo é como uma força que impulsiona ou gera o pensar crítico. Ele se faz através da confiança de um polo no outro, sendo uma consequência óbvia.

Nesta perspectiva, entendemos que, em uma educação como prática da liberdade, o diálogo só é possível se houver um diálogo aberto e informal, com uma relação horizontal e para negociação de ideias. O diálogo aberto e informal não é uma discussão guerreira, polêmica, entre sujeitos que não têm a intenção de comprometer-se com a pronúncia verdadeira do mundo (FREIRE, 2011a). Só pode acontecer quando houver iniciativas, incentivos, afetividade, apoio e compreensão.

A relação horizontal no diálogo, para Freire (2011b), significa uma ruptura com os esquemas de diálogos verticais, com a superação da estrutura da relação dominante, entre educador e educando. Ou seja, não existe hierarquia, mas sim a busca por uma relação de iguais, de indivíduos como sujeitos que ensinam e aprendem juntos, em um processo sem centro, para o acolhimento e a negociação de ideias. Portanto, o acolhimento de ideias no diálogo requer a exposição das divergências, da diversidade e das diferenças, para que os sujeitos possam construir um sentido coletivo do seu mundo. Por isso, o diálogo é a base do encontro dos homens quando tratam do mundo, para pronunciá-lo (FREIRE, 2011b). A palavra no diálogo tem duas dimensões, a ação e a reflexão que resultam na práxis. A ação que exclui a reflexão nega a práxis e a palavra converte-se em ativismo. A reflexão que exclui a ação transforma-se em verbalismo e também se esgota a dupla dimensão ação-reflexão. E ambos impossibilitam o verdadeiro diálogo (FREIRE, 2011a).

Por isto, é no diálogo que podemos olhar o mundo e nossa existência em sociedade como processo em construção de uma realidade inacabada e em transformação. Uma educação para o diálogo também se faz necessária na medida em que é problematizadora. Vale ressaltar que problematizar "não é sloganizar e sim exercer uma análise crítica sobre a realidade problema". (FREIRE, 2011b, p. 229).

Temos como referencial que a problematização promove a humanização, autonomia, o pensar autêntico, reflexivo e consciente através do diálogo. Para Freire (2011a), a 
problematização requer o desenvolvimento de uma consciência crítica para identificação das situações desafiadoras ou problemas concretos, ou seja, que partam do contexto. A problematização é o desafio da ascensão da ingenuidade para a criticidade (FREIRE, 2011a). Dessa forma, deve surgir da realidade concreta que o sujeito vive, porque é no momento em que o sujeito diz a sua palavra em relação ao modo como ele interpreta o mundo e que, a partir desta compressão, passa a agir e a buscar a ação para transformação dessa realidade. $\mathrm{Ou}$ seja, a emancipação através da reflexão, haja vista que a libertação autêntica não é uma coisa oca que só faz sentindo em si e a quem deposita, mas, sim, resultante de um processo de humanização (FREIRE, 2011b).

Por isso, defendemos que a educação transformadora que deve ser buscada tenha como fundamento a proposta de uma Educação para Liberdade. Que, de maneira resumida, significa: promover espaços de diálogos problematizadores e horizontais para refletir sobre as questões e temas circundantes em nossa sociedade.

\section{A PESQUISA}

A partir deste referencial teórico, destacamos que uma formação crítica para a utilização de TDIC tem como pré-requisito a existência de diálogo e a inclusão do contexto. Isto é, tal formação só poderia ocorrer em um ambiente dialógico que considera e inclui o contexto dos alunos. Este ambiente propício cria a condição para a existência de reflexão e ação, que se complementam na formação do sujeito para a ação transformadora no mundo. A partir disso, surgem as categorias de análise para a pesquisa, expressos na Figura 1.

Figura 1 - Categorias de Análise

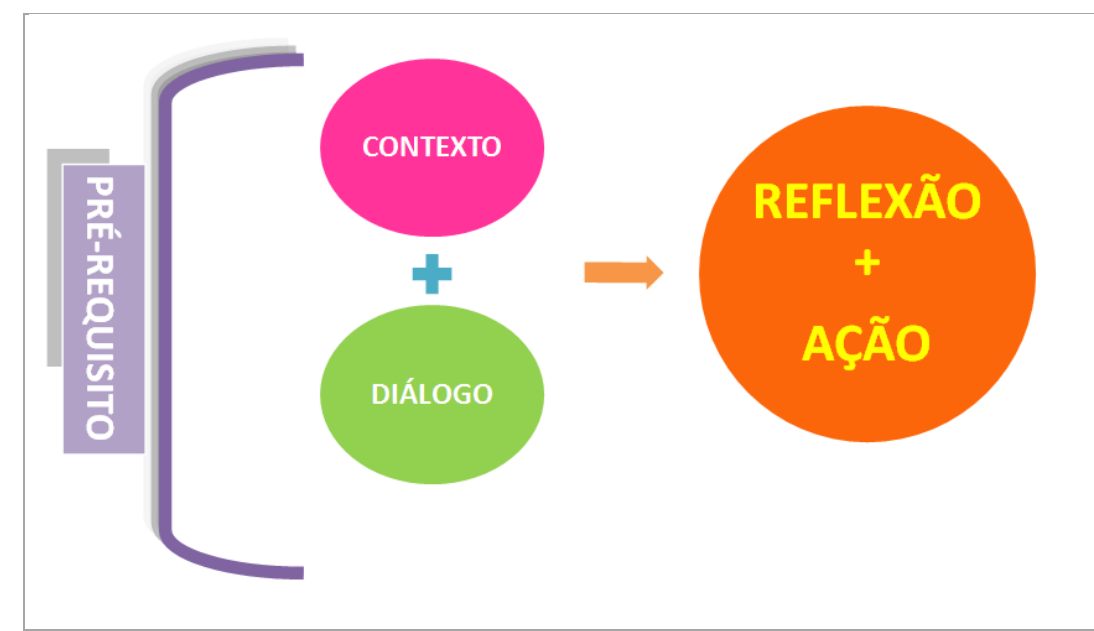

Fonte: Souto, 2013.

Para o desenvolvimento desse modelo, partimos dos seguintes pressupostos: a) contexto é o desenvolvimento de uma consciência crítica que deve partir da identificação de 
situações desafiadoras ou problemas vivenciados pelos próprios indivíduos; b) o diálogo é a condição necessária para os indivíduos pronunciarem-se, denunciarem-se, confrontarem-se a respeito do mundo, da existência em sociedade, para a construção de um sentido coletivo; c) a reflexão e a ação, são elementos constantes e resultantes dessa base, principalmente quando se objetiva a emancipação para transformação política e social do sujeito crítico.

Portanto, com base nesse modelo conceitual, nos debruçamos para investigar a oferta de uma disciplina na busca de identificar a existência das quatro categorias elencadas como determinantes para a formação crítica: contexto, diálogo, reflexão e ação. Para além de uma busca de simples existência, procuramos conhecer como elas haviam ocorrido, a partir da observação e da percepção dos docentes e discentes envolvidos.

A ideia inicial tinha o objetivo de analisar a prática pedagógica da disciplina e as formas da apropriação das TDIC pelos discentes (DI), através da principal atividade da disciplina, que tratava de resolver um problema pedagógico do ensino de ciências através de um projeto didático. Contudo, devido à riqueza dos debates que ocorreram na equipe docente, resolvemos ampliar a pesquisa para a perspectiva da docência enquanto espaço de reflexão e ação para a formação continuada da equipe docente (DO), que chamamos de metadisciplina.

Nesta dimensão, buscamos analisar a prática pedagógica como espaço de possibilidade para a formação crítica a partir da perspectiva da equipe docente, acerca do planejamento, do desenvolvimento e da avaliação. De modo que a análise final dos dados se desdobrou em duas dimensões chamadas de disciplina e metadisciplina.

A coleta de dados se deu a partir de fontes variadas, o que resultou em uma grande quantidade de dados, especialmente por se tratarem de espaços dialógicos de interação social. Junto da sua riqueza, trouxeram também a dificuldade de tratamento a partir de uma metodologia qualitativa, e tal desafio foi superado com o suporte do software Web Qualitative Data Analysis WebQDA ${ }^{3}$, a partir da codificação de todas as fontes e do cruzamento automático de variáveis.

No âmbito dos modelos conceituais, criamos, para cada categoria, indicadores diferentes, que representam o que identificamos ser necessário para analisar como o contexto, o diálogo, a reflexão e a ação, aconteceram nas duas dimensões da análise, na disciplina e na metadisciplina. Além dos indicadores, temos a delimitação de variáveis. Neste sentido, as variáveis são os desdobramentos dos indicadores e categorias, ou seja, "como se representam", nos espaços investigados da disciplina, a presença dos pressupostos essenciais para análise da formação do sujeito crítico. Nas figuras abaixo apresentamos o desenho da

\footnotetext{
${ }^{3}$ WebQDA, disponível em $\underline{w w w . w e b q d a . c o m / s o f t w a r e ~}$
}

Comun. \& Inf., Goiânia, GO, v. 17, n. 2, p. 88-103, jul./dez. 2014 
pesquisa criado, nas Figuras 2 e 3 para a dimensão da disciplina e nas Figuras 4 e 5 para a dimensão da metadisciplina.

Figura 2 - Categoria de Análise-Dimensão da Disciplina: Contexto e o Diálogo

\begin{tabular}{|c|c|c|}
\hline \multicolumn{3}{|c|}{ DISCIPLINA } \\
\hline CATEGORIA & INDICADOR & VARIÁVEL \\
\hline \multirow{4}{*}{ 1. CONTEXTO } & $\begin{array}{l}\text { 1.a - Aproximação do tema do projeto } \\
\text { com a sua área; }\end{array}$ & $\begin{array}{l}\text { - Aproximação de temas de interesses; } \\
\text { - Relação do contexto -> projeto; }\end{array}$ \\
\hline & 1.b - Exposição do próprio contexto; & - Relativo ao conteúdo; \\
\hline & 1.c Aplicação do projeto no contexto; & - Desdobramento do projeto $\rightarrow$ contexto; \\
\hline & $\begin{array}{l}\text { 1.d - Compartilha conteúdo e/ou } \\
\text { informação própria; }\end{array}$ & - Troca efetiva do conteúdo/informação; \\
\hline \multirow[t]{3}{*}{ 2. DIÁLOGO } & 2.a - Relação Horizontal; & $\begin{array}{l}\text { - Não existe hierarquia; } \\
\text { - } \quad \text { Rem constrangimento; } \\
\text { - } \\
\text { - Acolhimento das ideias; } \\
\end{array}$ \\
\hline & 2.b - Diálogo Aberto/Informal & $\begin{array}{l}\text { - Iniciativa para o diálogo; } \\
\text { - } \quad \text { Convite/incentivo a participação; } \\
\text { - } \quad \text { Afetividade/apoio/compreensão; }\end{array}$ \\
\hline & 2.c - Negociação de ideias & $\begin{array}{l}\text { - Exposição da divergência/diversidade } \\
\text { - Construção de um sentido coletivo; }\end{array}$ \\
\hline
\end{tabular}

Autor: Souto, 2013.

Figura 3 - Categoria de Análise - Dimensão da Disciplina: Reflexão e Ação.

\begin{tabular}{|c|c|c|}
\hline \multicolumn{3}{|c|}{ DISCIPLINA } \\
\hline CATEGORIA & INDICADOR & VARIÁVEL \\
\hline \multirow[t]{2}{*}{ 3. REFLEXÃO } & 3.a - Reconhecer o problema (conteúdo específico) & $\begin{array}{l}\text { - Escolha do tema; } \\
\text { - Relevância do tema para o } \\
\text { Ensino; }\end{array}$ \\
\hline & $\begin{array}{l}\text { 3.b - Identificar alternativas ao problema com uso de } \\
\text { TIC }\end{array}$ & - Escolha do Recurso; \\
\hline \multirow[t]{2}{*}{ 4. AÇÃO } & $\begin{array}{l}\text { 4.a - Escolha da Solução } \\
\text { (justificativa do problema) }\end{array}$ & $\begin{array}{l}\text { - Análise da apropriação do } \\
\text { recurso para atender as demandas } \\
\text { específicas do tema (do Ensino de } \\
\text { Ciências); }\end{array}$ \\
\hline & $\begin{array}{l}\text { 4.b - Ação para a Mudança } \\
\text { (desenvolvimento) }\end{array}$ & $\begin{array}{l}\text { - Análises do desenvolvimento do } \\
\text { projeto e avaliação dos grupos; }\end{array}$ \\
\hline
\end{tabular}

Autor: Souto, 2013.

Figura 4 - Categorias de Análise - Dimensão da Metadisciplina: Contexto e Diálogo

\begin{tabular}{|c|c|c|}
\hline & \multicolumn{2}{|c|}{ METADISCIPLINA } \\
\hline CATEGORIA & INDICADOR & VARIÁVEL \\
\hline \multirow[t]{2}{*}{ 1. CONTEXTO } & $\begin{array}{l}\text { 1.a - Abertura e Flexibilidade no } \\
\text { Currículo } \\
\text { (inclusão do contexto dos alunos); }\end{array}$ & $\begin{array}{l}\text { Solicitações/Dúvidas/Sugestões/ } \\
\text { apresentadas pelos alunos foram } \\
\text { consideradas; }\end{array}$ \\
\hline & $\begin{array}{l}\text { 1.b - Inclusão das necessidades } \\
\text { específicas das áreas no planejamento } \\
\text { (Ensino de Ciências) }\end{array}$ & $\begin{array}{l}\text { - Adaptação do currículo à demanda da } \\
\text { área; }\end{array}$ \\
\hline \multirow[t]{3}{*}{ 2. DIÁLOGO } & 2.a - Relação Horizontal; & $\begin{array}{l}\text { - Não existe hierarquia; } \\
\text { - } \quad \text { Sem constrangimento; } \\
\text { - Relação de iguais; } \\
\text { - } \quad \text { Acolhimento das ideias; } \\
\end{array}$ \\
\hline & 2.b - Diálogo Aberto/Informal & $\begin{array}{l}\text { - Iniciativa para o diálogo; } \\
\text { - } \quad \text { Convite/incentivo a participação; } \\
\text { - } \quad \text { Afetividade/apoio/compreensão; }\end{array}$ \\
\hline & 2.c - Negociação de ideias & $\begin{array}{l}\text { - Exposição da divergência/diversidade } \\
\text { - Construção de um sentido coletivo; }\end{array}$ \\
\hline
\end{tabular}

Autor: Souto, 2013. 
Figura 5- Categorias de Análise - Dimensão da Metadisciplina: Reflexão e Ação

\begin{tabular}{|c|c|c|}
\hline & \multicolumn{2}{|c|}{ METADISCIPLINA } \\
\hline CATEGORIA & INDICADOR & VARIÁVEL \\
\hline \multirow[t]{2}{*}{ 3. REFLEXÃO } & $\begin{array}{l}\text { 3.a - Reconhecer o problema } \\
\text { (dificuldade de ensinar a apropriação crítica das TIC) }\end{array}$ & $\begin{array}{l}\text { - Identificando o nosso problema de } \\
\text { ensino, que é o ensino da apropriação } \\
\text { critica das tic; }\end{array}$ \\
\hline & $\begin{array}{l}\text { 3.b - Identificar alternativas ao problema } \\
\text { (estratégias didáticas para a apropriação crítica - } \\
\text { instrumental x crítica) }\end{array}$ & $\begin{array}{l}\text { - Reconhecendo alternativas pra } \\
\text { resolver o problema de ensino da } \\
\text { apropriação das tic; }\end{array}$ \\
\hline \multirow[t]{3}{*}{ 4. AÇÃO } & $\begin{array}{l}\text { 4.a - Escolha da Solução } \\
\text { (estratégia didática - o projeto como espaço de vivência da } \\
\text { apropriação crítica) }\end{array}$ & $\begin{array}{l}\text { - Definindo o projeto como a estratégia } \\
\text { didática adequada pra apropriação das } \\
\text { tic - a formação critica; }\end{array}$ \\
\hline & $\begin{array}{l}\text { 4.b - Ação para a Mudança } \\
\text { (Acompanhamento da equipe docente sobre } \\
\text { desenvolvimento do projeto - problematização sobre } \\
\text { projeto como espaço de possibilidade) }\end{array}$ & $\begin{array}{l}\text { - Problematizando os desafios e } \\
\text { contradições da experiência de ter } 0 \\
\text { projeto como o espaço de possibilidade } \\
\text { desta formação critica - da ação da } \\
\text { solução que escolhemos - a estratégia } \\
\text { didática do projeto }\end{array}$ \\
\hline & 4.c - Reflexão para uma nova ação & $\begin{array}{l}\text { - Propostas de encaminhamentos em } \\
\text { nova oferta. Início de um novo ciclo. } \\
\text { Reflexão para a nova ação. }\end{array}$ \\
\hline
\end{tabular}

Autor: Souto, 2013.

A pesquisa foi desenvolvida na disciplina de Introdução ao Uso das Tecnologias da Informação e Comunicação na Educação. Esta disciplina é oferecida como optativa pelo departamento de Metodologia do Ensino - MEN, registrada como MEN5911, para os Cursos de Licenciatura em Física e Licenciatura em Ciências Biológicas da Universidade Federal de Santa Catarina, no primeiro semestre de 2012. A disciplina teve por objetivo promover uma apropriação crítica e criativa dos recursos tecnológicos através da vivência em situações de aprendizagem com o uso de TIC e encontra-se organizada de maneira que o aluno possa vivenciar as diferentes tecnologias disponíveis para inteirar-se das recentes discussões teóricas e experiências sobre Educação Científica e as Tecnologias da Informação e Comunicação. A atividade didática principal desta disciplina, que utiliza o Moodle ${ }^{4}$ de Apoio aos Cursos Presencias, foi a elaboração de um projeto de apropriação de TDIC na Educação Científica.

\section{ALGUNS RESULTADOS}

Nas duas dimensões, realizamos uma análise de conteúdo dos discursos a partir da codificação de todas as fontes através de pesquisa de matriz e pesquisa de código no software WebQDA. A partir daí, o software permitiu operar cruzamentos automáticos nesses dados, através da estrutura de questionamento orientada. Porém cabe ressaltar que neste artigo apresentaremos somente a pesquisa de matriz.

\footnotetext{
${ }^{4}$ Moodle: Modular Object-Oriented Dynamic Learning Environment
}

Comun. \& Inf., Goiânia, GO, v. 17, n. 2, p. 88-103, jul./dez. 2014 
Nesta pesquisa desdobramos o problema de pesquisa geral (da dissertação): como promover a formação crítica através das tecnologias digitais da informação e comunicação no Ensino de Ciências?- em alguns questionamentos que apresentamos abaixo com uma amostra de como os resultados puderam ser analisados.

- Houve mais reflexão e ação na dimensão da disciplina ou na dimensão da metadisciplina?

- Houve mais reflexão onde existiu contexto e diálogo?

- Houve mais ação onde existiu contexto e diálogo?

- A reflexão e a ação foram proporcionais?

- Houve mais contexto, diálogo, reflexão e ação no início, meio ou fím da disciplina?

Tendo em vista estas questões gerais, criamos questionamentos específicos para a pesquisa de matrizes e pesquisa de código no software WebQDA. Por isto, os questionamentos que orientam a pesquisa de matrizes, na dimensão da disciplina, foram:

- Quais são as contribuições dos docentes e discentes no contexto $(1 \mathrm{a}+1 \mathrm{~b}+1 \mathrm{c}+1 \mathrm{~d})$ ?

- Houve diálogo $(2 a+2 b+2 c)$ na relação DO-DI e DI-DI?

- Qual a perspectiva dos discentes sobre a reflexão $(3 a+3 b)$ e a ação $(4 a+4 b)$ no projeto de apropriação das TDIC no EC?

As questões da dimensão da metadisciplina seguem a mesma lógica da anterior, mas com outros indicadores e variáveis. Neste caso, as questões orientadoras da pesquisa foram:

- Nas reuniões da equipe docente, foram discutidas as questões relativas à inclusão do contexto $(1 \mathrm{a}+1 \mathrm{~b})$ ?

- Houve diálogo $(2 a+2 b+2 c)$ na relação DO-DO?

- Quais os desafios da equipe docente sobre a reflexão $(3 a+3 b)$ e ação $(4 a+4 b+4 c)$ no projeto de apropriação das TDIC na disciplina?

- Quais as diferenças da reflexão $(3 a+3 b)$ e ação $(4 a+4 b+4 c)$ dos docentes do EC e Ñ-EC?

- Qual a perspectiva dos DO na ação (4c)?

A identificação da existência de uma categoria em seus indicadores pode ser compilada no detalhe dos discursos, e isto nos trouxe importantes respostas. Por exemplo, para verificar a existência da categoria ação na dimensão da disciplina, codificamos as fontes internas do Encontro Presencial e na Rubrica de Auto Avaliação e percebemos que quando houve ação, ela se distribuiu pelos indicadores de forma desequilibrada: $69 \%$ na escolha da ação e $31 \%$ na ação para a mudança. O que demonstra que, ao menos na perspectiva dos discentes, o objetivo da disciplina (produzir um recurso digital a partir de um problema de ensino) se mostrou um pouco frágil, como mostra o excerto abaixo, pois as questões das 
dificuldades de trabalho com a ferramenta tecnológica ficaram mais evidentes do que o uso da ferramenta para atingir um objetivo pedagógico, ou seja, o objetivo de ensino.

Discente (não identificado): "Orecurso Blog auxilia na forma de se abordar o conteúdo didático e garante a autonomia do aluno de acessar os conteúdos da maneira que lhe for mais conveniente." (Fonte: Extratos dos Dados de Pesquisa)

No entanto, a partir do extrato dos dados abaixo, percebemos evidências que o trabalho docente estava orientado para questões contrárias à posição do discente citado acima.

Docente (não identificado): "Mas como a tecnologia pode, tá promovendo um mudança, no professor, na perspectiva de uma nova metodologia, uma nova pedagogia, que ele pensa, ele reflete sobre a sua prática, e ressignifica a sua prática, mais adequada ao contexto atual que é um contexto de um mundo mediado por tecnologia. Enfim, né, esta é a discussão da nossa disciplina". (Fonte: Extratos dos Dados de Pesquisa)

Este extrato dos dados é revelador, pois se percebe a necessidade de um trabalho ainda mais orientado pela docência, pois, apesar desta ser uma preocupação constante da equipe docente, somente poucos discentes foram sensibilizados, como mostra o raro extrato dos dados abaixo.

Discente (não identificado):“Achava que o uso dos TIC era apenas para dizer estou usando tecnologias, estou inovando utilizando o computador e deu, sem objetivos definidos apenas por usar. Pensava que uma aula tradicional com experimentos reais era o suficiente, esclarecedor para os temas abordados/ Tinha um certo bloqueio ao uso e TIC. Ao decorrer das atividades oferecidas pela disciplina, pude ver como podemos utilizar esses recursos na área da educação e da ciência. E, principalmente, com a escolha do tema, que me fez entender que nem todo assunto podemos demonstrar com experimentos em sala de aula, ou com um texto de um livro didático. Com artigos e a necessidade pude conhecer e entender, através de cada tema e seus objetivos, pude reconhecer os recursos e as ferramentas necessárias". (Fonte: Extratos dos Dados de Pesquisa)

O problema da apropriação crítica da TDIC ainda é relevante para o campo da formação de professores, pois um grande desafio permanece na restrita compreensão das tecnologias digitais no processo de ensino-aprendizagem apenas como mera ferramenta auxiliar (PRETTO, 2013).

Outro exemplo da análise dos dados é a comparação evolutiva das categorias e indicadores em uma linha temporal, o que permitiu esclarecer sua ocorrência durante a oferta da disciplina e relacioná-la às ações didáticas específicas. Na ocorrência das categorias, 
observamos que houve uma incidência maior do contexto e do diálogo no meio da disciplina, enquanto a reflexão e a ação ocorreram mais no fim da disciplina, como mostra a Figura 6.

Figura 6 - Dimensão da Disciplina a partir dos extratos dos dados dos Discentes

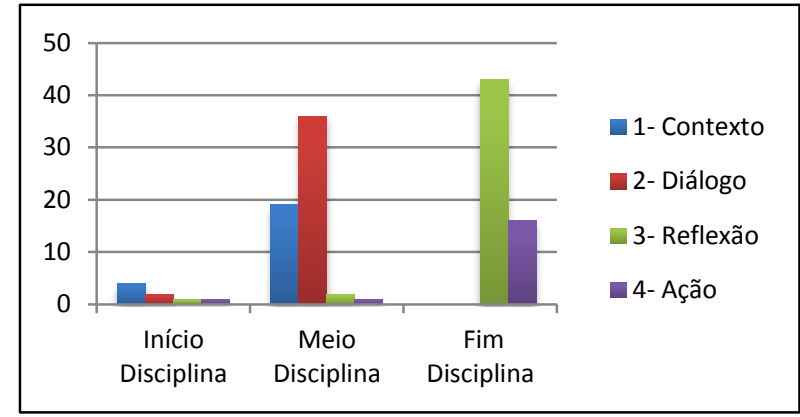

Autor: Souto, 2013

Cabe destacar que os picos de incidência confirmam que as categorias diálogo $e$ contexto são pré-requisitos da ação e da reflexão. Isto porque houve mais contexto e diálogo no momento em que os alunos escolheram a temática e o recurso, assim como negociaram as ideias para o desenvolvimento do projeto. Além disso, houve maior incidência de reflexão e ação no fim da disciplina, que é o momento em que os alunos desenvolveram o projeto, o recurso de TDIC, socializaram com a turma, bem como fizeram a autoavaliação e avaliação entre pares. Isto se confirma no discurso dos discentes:

Discente (não identificado): "O uso das Tecnologias da Informação e Comunicação (TCI) no Ensino de Ciências pra mim melhorou e muito. Com o desenvolvimento do projeto consegui aprender mais sobre estes recursos e promover um debate maior sobre como estar utilizando-os. Penso que estes estão cada vez mais perto e junto com os alunos, então utilizamos para ajudar o aluno na criação e facilitação da aprendizagem". (Fonte: Extratos dos Dados de Pesquisa)

$\mathrm{Na}$ percepção dos docentes (dimensão da metadisciplina), observamos que a categoria Ação se destaca mais no meio da disciplina, como mostra a Figura 7.

Figura 7 - Dimensão da Metadisciplina a partir dos extratos dos dados dos Docentes

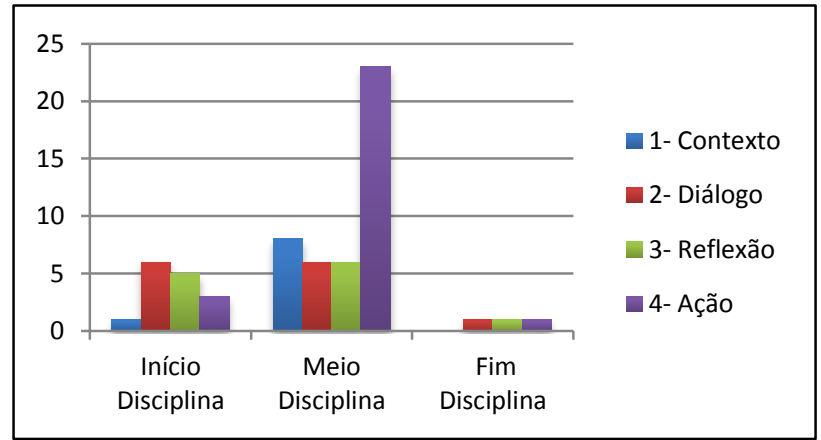

Autor: Souto, 2013. 
Esta figura gera indícios de que a ação docente no meio da disciplina foi o fator determinante e teve desdobramentos na reflexão e ação dos discentes no fim da disciplina. Cabe destacar, que na pesquisa de matriz, os extratos obtidos revelam que a ação docente no meio da disciplina corresponde à elaboração de estratégias didáticas para o desenvolvimento e a avaliação do projeto. Ou seja, aqui os docentes estavam refinando os critérios para avaliação do projeto (ideia inicial, objetivos, fundamentação teórica) e o produto.

\section{CONCLUSÕES}

Neste estudo, partimos de uma inquietação baseada na constatação de que estamos diante de novas configurações sociais e culturais que inevitavelmente acontecem e são catalisadas pela presença das TDIC. Esse novo contexto, a cultura digital, traz novos desafios para a educação, especialmente para os professores. Enquanto as políticas públicas focam na viabilização do acesso (ainda precário) aos equipamentos e à Internet, os professores não são formados para uma apropriação crítica e criativa das tecnologias (como conteúdo e/ou como ferramenta pedagógica) e se deparam com alunos nativos e confortáveis na cultura digital. $\mathrm{O}$ desafio para o professor se desdobra rapidamente no desafio para a formação de professores.

Diante desse conflito, investigamos a disciplina de Introdução ao Uso da TIC na Educação nos cursos de licenciatura em Ciências Biológicas e Física da UFSC, para refletir sobre a disciplina como um espaço de possibilidade na formação de futuros professores para uma apropriação crítica dos recursos digitais no Ensino de Ciências.

Usamos como metodologia de pesquisa a concepção da Investigação-Ação, que nos permitiu uma pesquisa qualitativa e uma pesquisa quantitativa com envolvimento da pesquisadora na ação pedagógica analisada, além de possibilitar a elaboração de uma ferramenta de exploração das práticas pelos professores com vistas à compreensão da pesquisa como movimento cíclico e permanente do processo educacional. No processo de pesquisa, realizamos algumas entrevistas e também observamos a disciplina, em busca de relacionar a prática pedagógica à percepção dos envolvidos.

Para o tratamento e análise dos dados, desenvolvemos um Modelo Conceitual a partir dos pressupostos da teoria freirianade uma educação dialógica problematizadora, que se tornou o desdobramento analítico desta proposta de investigação. O modelo apresenta duas dimensões, a dimensão da disciplina e a dimensão da metadisciplina, isto é, a investigação sobre a disciplina como prática pedagógica, mas também como espaço de possibilidade para a 
docência. As duas dimensões têm o contexto, diálogo, reflexão e açãocomo elementos essenciais para a formação crítica e o modelo explora a disciplina na sua potencialidade de promover a formação crítica a partir do reconhecimento e da promoção destas categorias em diferentes momentos da prática.

Nossa busca foi de explorar a disciplina segundo o recorte teórico e modelo criado. Salientamos que o modelo conceitual foi criado com a perspectiva de oferecer um instrumento de exploração da própria prática por professores e não de uma avaliação externa. Isto é, apresenta-se como uma opção para os docentes que buscam refletir e analisar suas práticas pedagógicas mediadas pelas TDIC. Ele permite uma investigação sistematizada para aqueles que compartilham da nossa preocupação com uma formação crítica diante da cultura digital, especialmente através de uma educação problematizadora como a que defendemos.

Como desenho de pesquisa inovador, enfrentamos alguns desafios, como a análise qualitativa de grande quantidade de dados, que foi possível avançar devido ao uso de software apropriado para este fim, o WebQDA. Contudo, o pouco espaço de tempo para a aprendizagem da nova ferramenta após a coleta de dados, resultou na exploração limitada do recurso para outros cruzamentos de dados que poderiam enriquecer ainda mais a análise. Como, por exemplo, relacionar prática docente e aprendizagem discente a partir do estudo comparado da disciplina e da metadisciplina na linha temporal da oferta (que apontamos neste artigo).

Acreditamos que esta pesquisa contribui para a formação inicial e continuada de professores, por apresentar algumas possibilidades de pesquisar a própria prática docente com o objetivo de trazer elementos essenciais da educação problematizadora para as suas ações pedagógicas na cultura digital.

\section{REFERÊNCIAS}

BELLONI, Maria L. O que é mídia-educação. 2. ed. Campinas, São Paulo: Autores Associados, 2005.

BONILLA, M. H.; PRETTO, N. Inclusão digital. Polêmica contemporânea. Salvador: EDUFBA, 2011.

FANTIN, Monica. Mídia-Educação: conceitos, experiências, diálogos Brasil-Itália. Florianópolis: Cidade Futura, 2006.

FREIRE, PAULO. Educação como prática para a liberdade. 14. ed. Rio de Janeiro. Paz e Terra, 2011.

FREIRE, PAULO. Pedagogia do oprimido. 50. ed. Rio de Janeiro. Paz e Terra, 2011b. 
GIROUX, Henry. Os professores como intelectuais: rumo a uma pedagogia crítica da aprendizagem. Porto Alegre: Artmed, 1997.

KELLNER, Douglas. A cultura da mídia: estudos culturais: identidade e política entre o moderno e o pós-moderno. Bauru: EDUSC, 2001.

MARTÍN-BARBERO, J. Oficio do cartógrafo: travessias latino-americanas da comunicação na cultura. São Paulo: Loyola, 2004.

PRETTO, Nelson De Lucca. Reflexões: ativismo, redes sociais e educação. Salvador: EDUFBA, 2013.

RÜDIGER, Francisco. As teorias da cibercultura: perspectivas, questões e autores. Porto Alegre: Sulina, 2011.

Recebido em: 09/09/2014

Aceito em: 27/09/2014

Publicado em: 10/12/2014 